Short Communication

\title{
Preparation of High Contents of Pyridinic and Pyrrolic- Nitrogen Doped Activated-Carbon from Pyrolysis of Purple Cabbage for the Catalysis of Oxygen Reduction Reaction
}

\author{
Jing Cheng ${ }^{1+}$,Yao Liu ${ }^{1+}$, Yanrong $\mathrm{Li}^{1+}$, Wenli Liao ${ }^{1+}$, Zhongbin $\mathrm{Li}^{1}$, Chaozhong Guo ${ }^{1, *}$, \\ Wei-Zhong Zhang ${ }^{2}$, Rong $\mathrm{Hu}^{1, *}$, Qin-Rong Kang ${ }^{2}$, Jianglan Liao ${ }^{1}$, Wensheng Li ${ }^{4}$, Linzheng Liao ${ }^{1, *}$ \\ ${ }^{1}$ Research Institute for New Materials Technology, School of Materials and Chemical Engineering, \\ Engineering Research Center of New Energy Storage Devices and Applications, Chongqing University \\ of Arts and Sciences, Chongqing 402160, China. \\ ${ }^{2}$ School of Resources and Civil Engineering, Wuhan Institute of Technology, Hubei 430070, China. \\ ${ }^{3}$ College of Chemistry and Chemical Engineering, Chongqing University, Chongqing 400044, China. \\ ${ }^{4}$ College of Materials Science and Engineering, College of Chemistry and Chemical Engineering, \\ Chongqing University of Technology, Chongqing 400054, China. \\ ${ }^{\dagger}$ These authors contributed equally to this work and should be considered as co-first authors. \\ *E-mail: guochaozhong1987@163.com (C. Guo); 35502657@qq.com (R. Hu); 284188178@qq.com \\ (L. Liao)
}

doi: $10.20964 / 2018.11 .81$

Received: 15 April 2018 / Accepted: 8 June 2018 / Published: 1 October 2018

Effective conversion of reproducible organic biomass into valuable carbon material is very important for renewable energy technology. In this study, here we develop a unique strategy to design a nitrogendoped carbon-based electrocatalyst for oxygen reduction reaction (ORR) via successful pyrolysis of purple cabbage combining with $\mathrm{ZnCl}_{2}$ activation and acid-leaching processes. It is found that this carbon material show high ORR catalysis performance with an ORR onset potential of $\sim 0.96 \mathrm{~V}$ versus RHE and a half-wave potential of $\sim 0.8 \mathrm{~V}$, slightly lower than that of the commercial Pt/C catalyst in $0.1 \mathrm{~mol} \mathrm{l}^{-1} \mathrm{KOH}$ solution. The high ORR activity mainly derives from high contents of pyridinic- and pyrrolic-nitrogen inside the prepared carbon material. Besides, compared to the $\mathrm{Pt} / \mathrm{C}$ catalyst, the prepared catalyst also exhibits excellent long-term stability, which can be considered as a promising carbon-based ORR catalyst for fuel cells.

Keywords: biomass material, oxygen reduction, porous carbon, electroncatalyst

\section{$\underline{\text { FULL TEXT }}$}


(C) 2018 The Authors. Published by ESG (www.electrochemsci.org). This article is an open access article distributed under the terms and conditions of the Creative Commons Attribution license (http://creativecommons.org/licenses/by/4.0/). 